\title{
Research on the Construction of Flipped Classroom Teaching Model of Analytical Chemistry
}

\author{
Yongpeng $\mathrm{XIE}^{1, \mathrm{a}}$ Yingge Yang ${ }^{2, \mathrm{~b}}$ \\ 1 College of Education Science and Technology, Xuzhou Institute of Technology, Xuzhou, \\ Jiangsu, 221006, China \\ 2 Department of Bioengineering, Xuzhou Vocational college of Bioengineering, Xuzhou, Jiangsu, \\ 221006, China \\ aemail: xieyongpeng@163.com bemail:ygyang_1982@163.com
}

\begin{abstract}
Keywords: Flipped classroom; Massive open online courses; Virtual experiment; Network communication platform; Analytical chemistry;
\end{abstract}

\begin{abstract}
Flipped classroom is a new teaching mode. The flipped classroom has injected fresh vigor into the modern classroom teaching. The analytical chemistry course was took as an example to design flipped classroom teaching model. Students should make full use of open education resources, virtual experiment network, communication platform outside the classroom. Teachers can design multi-level problems for students to guide and supervise inside the classroom. Furthermore, teachers can organize the students to cooperate with the group. So, teachers have plenty of time to communicate and discuss with students. In flipped classroom, the teaching content is not reduced, and the teaching standards are not lowered. Students learn the contents of analytical chemical actively and happily. In the process of the development of education information, flipped classroom will have an impact on the existing teaching mode.
\end{abstract}

\section{Introduction}

Flipped classroom is a new teaching mode. Flipped classroom means that events that have traditionally taken place inside the classroom now take place outside the classroom and vice versa. The use of learning technologies, particularly multimedia, provide new opportunities for students to learn, opportunities that are not possible with other media(Lage et al, 2000). The traditional teaching mode is that the teacher teaches in class and the students finish their homework after class. Flipped classroom upside down the traditional teaching mode. Salman Khan is a leader in the implementation of flipped classroom. Khan Academy founded by him is famous for flipped classroom teaching mode. Micro video courses in Khan Academy were loved by many Students. Now, flipped classroom has evolved into a new teaching mode in the entire North American and even the whole world. The flipped classroom provides a new way for the education reform in our country.

Flipped classroom teaching mode has the characteristics of different from the traditional teaching mode. First, it reverses the traditional teaching ideas. Flip the classroom emphasis on the students' collaborative learning and teachers targeted guidance. Flipped classroom provides a way for the implementation of the student-center teaching mode. Flipped classroom truly teach students in accordance with their aptitude. Secondly, flipped classroom subvert the traditional teaching process. Students learn new knowledge before class. In class, students learn knowledge through team collaboration and teacher answering questions. Teachers provide students with targeted help. At the same time, the role of the teacher and the students is reversed. In the flipped classroom, students are the learner who initiative to internalized knowledge, the teacher is the leader, the resources provider, the classroom activity organizer. A typical flipped classroom approach provides students with access to online video lectures prior to in-class sessions so that students are prepared to participate in more interactive and higher-order activities such as problem solving, discussions, and debates(Hughes, 2012). The flipped classroom conforms to the development trend of our country's education informationization. The flipped classroom has injected fresh vigor into the modern classroom teaching. In the paper, the analytical chemistry teaching is used as a case to explore the concept of flipped classroom 


\section{The limitations of analytical chemistry traditional teaching mode}

Analytical chemistry is a comprehensive course. The chemical constituents, contents, structures and morphology of the substances are studied in analytical chemical. This course is a basic course for the majors such as pharmacy and pharmacy. The principle and methods of Titration analysis, chromatographic analysis, spectral analysis are widely used in pharmaceutical analysis, plant chemistry and pharmacy. This course plays an important role in the cultivation of students' standard operation, good professional practice ability and basic scientific research quality. Through the course of study, students can develop science, rigorous professional quality, while improve the ability of analyzing and solving the problem of pharmacy.

The analytical chemistry teaching involves various analytical methods and the use of the instrument, also involves formula derivation and curve drawing. Because of the limitation of teaching time, the traditional teaching methods which depend on the teacher's language and the multimedia display can't teach the students all the knowledge completely and vividly. Moreover, the traditional teaching mode influences the students' subjective thinking ability and limits the interaction between the teachers and students. The students' understanding of the related principles and techniques may be deviations. Students generally considered the curriculum difficult to learn, difficult to understand. Students' interest in learning and teaching quality of curriculum were influenced. Therefore, through the deepening of teaching reform, the change of teaching mode, the use of modern information technology to improve students' learning initiative and enthusiasm, reflect the dominant position of students has become the key to improve the teaching quality of the course.

\section{The construction of flipped classroom teaching model of analytical chemistry}

From the viewpoint of many scholars, combining with the actual teaching needs and the characteristics of learners, the analysis chemistry flipped classroom teaching model is constructed in Figure 1. The model is divided into before class and in class. Before class, teachers and students undertake different tasks. The teacher is responsible for making teaching resources, pushing open education resources related to analytical chemistry, arranging tasks, answering questions, etc. According to the teacher's arrangement, the students study independently. In class, the teacher guides the students to discuss and carry out individual instruction, accomplish the teaching activity such as consolidation exercise, independent inquiry, cooperative learning and so on. The mode emphasizes the communication and evaluation, and pays great attention to cultivate the students' independent learning ability before class, and pays more attention to the internalization of knowledge in the cooperative exploration. At the same time, teachers guide students to carry out in-depth exploration, in order to tap the potential of learner and stimulate the learners of learning motivation. Based on the above analysis, the analytical chemistry course was took as an example to design flipped classroom teaching model.

\begin{tabular}{|c|c|c|}
\hline outside the classroom & inside the classroom \\
\hline virtual experiment & & multi-level problem \\
open education resources & group cooperation \\
network communication platform & teacher-student interaction \\
\hline
\end{tabular}

\section{Design outside the classroom}

Figure 1 flipped classroom model in analytical chemical teaching

Make full use of open education resources 
Throughout history, educators and researchers have always been intrigued with the potential of technology to help transform education and improve student learning (Hew \& Brush, 2007).Rich learning resources is the basis of the flipped classroom. Fortunately, with the development of the open education resources (OER), more and more colleges and educational institutions shared the quality education resources. One such resource is the use of the Internet to deliver courses; typically known as Massive Open Online Courses (MOOCs). The rise of MOOCs not only makes the teachers feel the pressure, but also makes the analytical chemistry course ushered in a new round of development opportunity. If teachers can introduce MOOCs and various kinds of network teaching resources into analytical chemistry teaching reasonably, class time will be effectively saved.

Then, the teacher can carry out the advanced teaching methods such as heuristic teaching, task driven teaching, in order to improve the teaching quality of the analytical chemistry course and promote the cultivation of innovative talents with profound knowledge and broad vision. Under the background of MOOCS, the teacher can use the flipped classroom teaching mode. The students use online video resources to complete the knowledge learning before the classroom teaching and complete the transfer and deepening of knowledge in the classroom with teacher. MOOCs eased the limitation of class time to a certain extent. MOOCs not only make the teacher have sufficient time to carry out rich and colorful teaching activities in classroom teaching, but also make the teacher reconstruct the knowledge structure of analytical chemistry so as to cultivate students' innovation ability and the ability of independent research

For example, the teaching content of titration analysis can be divided into titration analysis overview, chemical equilibrium, titration analysis principle and titration analysis application. Teachers can arrange students to learn the teaching content of precipitation titration and titration analysis by themselves using video resources of analytical chemical in MOOCs platform. As the core knowledge points of this chapter have been taught in class, the students have already had the relevant knowledge When students learn the application of concrete analysis method by themselves. So, there is no difficulty for students. Through study on their own, the time of classroom teaching can be saved. Therefore, the teacher can have enough time to discuss teaching emphasis and difficulty such as chemical equilibrium, titration analysis curve, indicator selection and so on in more detail. Finally, Students can thoroughly understand the relevant concepts in the class, master the relevant calculation of the titration analysis, and can master the method and the main attention issues of the design and use of titration analysis.

Make full use of virtual experiment

Virtual experiments created by virtual reality can mobilize the learner's potential intelligence. Some knowledge points of analytical chemical are abstract, boring and difficult to understand. The use of virtual experiment can transform these knowledge points from abstract to concrete, from static to dynamic, from micro to macro. Virtual experiment will explain the knowledge points concise and easy to understand and dispel the obstacle in abstract thinking of students. For example, In the teaching course of titration analysis, only a few students have completed the titration analysis experiments, the majority of students have a lack of intuitive understanding of the whole titration process. In order to help students complete significance construction and understand the principle and design of the comprehensive experiment, teachers can fall back on the virtual experiment with characteristic of high immersion. Through a series of virtual experiments, students can complete the training of determination of total alkalinity in alkali ash and a series of titration analysis experiments in computer or smart mobile phone. Virtual experiment is characteristic of vivid picture and high immersion design, high involvement operation and timely feedback on the problem in operation, which greatly attracted the interest of students and the students can complete the training of titration analysis experiment in a relaxed atmosphere. Comprehensive understanding of titration analysis process effectively promote the students' understanding of the design of experiments. Students can be more targeted to the design of the experiment scheme. It is conducive to ensuring the effect of self-study.

Make full use of network communication platform 
The key factor of learning is the question. Compared with the traditional classroom, the advantage of flipped classroom is that it takes students to a teaching activity environment which take the problem as the main clue. When the students encountered the problems in the self-study, because there is no timely answer, they may forget the problems over a period of time. If they can get a timely answer, the learning effect will be better. Therefore, it is necessary to establish a platform for students to communicate the questions encountered in the learning process in time.

With the rapid development of Internet technology, the modern network platform emerges in endlessly. It is convenient for teachers and students to communicate effectively with these modern communication platforms. Before the analytical chemical teaching, teachers can establish the communication platform of analytical chemical course. Through communication platform, teachers can not only publish homework, upload courseware and teaching materials, but also answer the questions when students do exercises and design the experiment program. Because there no limit of the time and space, the communication efficiency between the teacher and the students is greatly improved. And when students encounter problems during the self-study and experiment design, they can also turn to teachers or other students immediately. Smooth communication can help students establish confidence in learning analytical chemistry, and help to implement the reform program.

\section{Design inside the classroom}

Multi-level problem

On the one hand, multi-level problem can check the effect of self-study, on the other hand, multi-level problem can guide students to actively think. Teachers can design multi-level problems for students to guide and supervise. For example, in the teaching content of titration determination of the contents of each component in the alkali ash with double indicator method, teachers can arrange for students following series of problems, such as: what conditions can mixed acid-base or polybasic acid be implemented stepwise titration? In this case, why should I use phenolphthalein and methyl orange as indicator? What is the components content when each indicator changes color? If it is not taken for a continuous titration instead of a parallel titration. What are the specific components when each indicator is changing? These problems play a role of outline. They can help students grasp the core knowledge. In addition, learning with problems can promote students to think and help students to understand the relevant contents. In addition to these minor issues, teachers will also design some comprehensive issues. The objective is that students can have the ability to design experiments, analyze problems and solve practical problems independently after studying the basic theory and the specific case.

Group cooperation

The flipped classroom realized the development of the students' interpersonal communication. The teaching inside the classroom is not only a kind of cognitive activity, emotional activity and practical activity, but also a kind of interpersonal activity. For the knowledge more difficult to understand, teachers can organize the students to cooperate with the group. It is in the interaction of cooperative inquiry between teachers and students that flipped classroom makes the students become the master of learning. Each student is not only the communicator of knowledge, but also the recipient of knowledge. The learning way of "everyone teaches me, I teach everyone" promote students to understand knowledge deeply. Because students want to teach others, they must carry out the fine processing of knowledge. Group cooperation in flipped classroom model explored not only the ability of the students to work together, the interpersonal skills, but also the students' collective sense of responsibility and honor.

Teacher-student interaction

Flipped classroom enhanced the interaction between the teachers and students. The most obvious change in the flipped classroom is more interactive between teachers and students in the classroom. The role of the teacher is transformed from the speaker to the students' learning partner. Teachers have plenty of time to communicate and discuss with students. In face-to-face classroom sessions, students have the opportunity to become more active and interactive through group activities rather than passively listening to lectures. Teachers in turn are able to commit more 
in-class time to monitoring student performance and providing adaptive and instant feedback to an individual or group of students (Fulton, 2012). Especially in the experiment class, the students will put forward a lot of questions after the completion of the experiment, even many unexpected difficulties may appear in the process of the experiment. Teachers can make full use of the characteristics of the students in order to guide students to operate reasonably. Furthermore, teachers can organize a variety of activities, such as group contests or exchange performances, to give full play to their active thinking.

\section{Conclusion}

In the course of analytical chemical, the introduction of flipped classroom and the use of modern information technology will improve the teaching quality and effect. The organization of teaching material and teaching process broaden the teachers' professional perspective. Analytical chemistry is one of the important basic courses. Teaching mode needs to be changed. The introduction of flipped classroom mode is to adapt to the change of students' learning habits and the development of the information technology. Flipped classroom requires students to convert from passive learning to active learning. Teachers should guide students to adjust their learning habits and rhythms. In order to guarantee the teaching effect, the teacher should communicate with the students in time. Teacher's examination is the important link to strengthen function of flipped classroom. There may be two cases. One is that the students answer is unreasonable, the teacher needs revise, interpret and discuss experiment design with students. The second situation may be the students' plan is reasonable, but the feasibility is poor. This still requires the teacher to communicate with students and try to inspire students' learning interest.

In the information age, the classroom is no longer the only place for acquiring knowledge, and the textbook is no longer the only carrier of knowledge. Students are willing to close to the electronic terminal. Students can learn using all kinds of resources at any time positively. The key in Flipped classroom is teach effectively. In the activity experience and cooperation, the students can effectively complete the cognitive internalization and knowledge construction. In this kind of teaching mode, the teaching content is not reduced, and the teaching standards are not lowered. Students learn the contents of analytical chemical actively and happily. In the process of the development of education information, flipped classroom will have an impact on the existing teaching mode.

\section{References}

[1]Lage,M. J., Platt, G. J., \& Treglia,M. (2000). Inverting the Classroom: A Gateway to Creating an Inclusive Learning Environment. The Journal of Economic Education, 31(1), 30-43.

[2]Hughes, H. (2012). Introduction to flipping the college classroom. In T. Amiel, \& B.Wilson (Eds.), Proceedings from world conference on educational multimedia, hypermedia and telecommunications 2012 (pp. 2434-2438). Chesapeake: AACE.

[3]Hew, K. F., \& Brush, T. (2007). Integrating technology into K-12 teaching: Current knowledge gaps and recommendations for future research. Educational Technology Research and Development, 55(3), 223-252.

[4]Fulton, K. (2012). Upside Down and Inside Out: Flip Your Classroom to Improve Student Learning. Learning \& Leading with Technology, 39(8), 12-17. 